\title{
АНАЛИЗ ПРИЧИН НАРУШЕНИЯ МОТОРНО-ЭВАКУАТОРНОЙ ФУНКЦИИ ЖЕЛУДКА У БОЛЬНЫХ С МЕТАБОЛИЧЕСКИМ СИНДРОМОМ
}

\section{ANALYSIS THE CAUSES OF GASTRIC MOTILITY DISORDERS IN PATIENTS WITH METABOLIC SYNDROME}

S. Chernukha

I. Viltsaniuk

Summary. The relationship between the parameters of carbohydrate and lipid metabolism, the duration of the disease, gender characteristics, body mass index, HOMA-IR index and ghrelin concentration in patients with metabolic syndrome (MS) and gastric motility disorders was studied. A significant decrease in the content of ghrelin was found in patients with excessive body mass index, impaired indicators of carbohydrate and lipid metabolism. A statistically significant deceleration of the gastric motility in the examined patients with metabolic syndrome was proved.

Keywords: metabolic syndrome, obesity, functional dyspepsia, gastric motility, stomach.

\section{Ввемение}

овременной науке известно более двадцати гастроинтестинальных гормоном и биологически активных веществ, так или иначе влияющих на моторику пищеварительного тракта. Моторно-эвакуаторная функция (МЭФ) желудка осуществляется благодаря большому количеству рефлекторных, гуморальных, нервных, миогенных связей и функциональной активности гастроэнтеропанкреатической эндокринной системы. В синтезе и секреции регуляторных пептидов участвуют гастроинтестинальные эндокринные клетки (ГЭК) и нейроны, которые непосредственно влияют на моторно-эвакуаторную функцию желудка $[1,2,4]$. В группу нейропептидов, которые ускоряют опорожнение желудка, относятся: грелин, гастрин, мотилин, бомбензин, нейротен-зин, субстанция $\mathrm{P}$, серотонин, опиатные пептиды и угнетающие моторику желудка (холецистокинин, се-
Чернуха Сергей Николаевич

К.м.н., Медицинская академия имени

С.И. Георгиевского Федерального государственного автономного образовательного учреждения высшего образования «Крымский федеральный университет имени В.И. Вернадского», г. Симферополь

Chernik1975@list.ru

Вильцанюк Ирина Александровна

К.м.н., дочент, Медицинская академия имени

С.И. Георгиевского Федерального государственного автономного образовательного учреждения высшего образования «Крымский федеральный университет имени В.И. Вернадского», г. Симферополь irav1975@list.ru

Аннотация. Изучена взаимосвязь между показателями углеводного и липидного обменов, длительностью заболевания, гендерными особенностями, индексом массы тела, индексом HOMA-IR и концентрацией грелина у больных метаболическим синдромом (МC) с нарушением моторно-эвакуаторной функции желудка. Установлено достоверное снижение содержания грелина у пациентов с избыточным индексом массы тела, нарушенными показателями углеводного и липидного обменов. Доказано статистически значимое замедление моторно-эвакуаторной функции желудка у обследованных пациентов с метаболическим синдромом.

Ключевые слова: метаболический синдром, ожирение, функциональная диспепсия, моторно-эвакуаторная функция, желудок.

кретин, глюкагон, вазоактивный интестинальный пептид и др.).

Поиск новых патогенетических механизмов развития и прогрессирования функциональной патологии желудочно-кишечного тракта под действием гастроинтестинальных гормонов по-прежнему актуален. В 1999 году японскими учеными открыт пептидний гормон - грелин (Ghrelin), содержащий 28 аминокислотных остатков. Существует две формы эндогенного лиганда: активная (гексатропин) и неактивная $[5,7,10]$. Более $80 \%$ циркулирующего грелина синтезируется и секретируется в кровь ГЭК, тогда как более $20 \%$ его выделяют другие органы - поджелудочная железа, желчный пузырь, почки и другие [10], в том числе гипоталамус [3]. Рецепторы к данному гормону находятся в различных органах и тканях: мозга, гипоталамусе, гипофизе, пищеводе, эндотелии, гладкомышечных волокнах сосудов в ки- 
шечнике, почках, костях, эндометрии, плаценте, яичках, миокарде, особенно большое количество их в поджелудочной железе и жировой ткани. Грелин стимулирует холин-, дофаминергическую нервные системы, обладая прокинетическим потенциалом и ускоряет сокращение мышц желудка. На современном этапе функциональные особенности грелина мало изучены. В большинстве публикаций изучают его влияние на различные функции человеческого организма, в том числе на гастроинтестинальная моторику, без учета физиологических особенностей его молекулярных фракций. Грелин способствует гипергликемии, так как обладает диабетогенных и анаболическими свойствами, регулируя процесс питания, рост и метаболизм. А инсулинорезистентность, которая характерна для пациентов с метаболическим синдромом (MC), подавляет синтез грелина. Таким образом, гипогрелинемию можно считать главным патогенетическим механизмом развития ожирения, МС и даже сахарного диабета 2 типа [6, 8]. Кроме того, доказана роль этого нейропептида в регулировании гемодинамики, за счет вазодилатирующего эффекта, а также влияния на апоптоз кардиомиоцитов [9]. Известно, что агонистов грелина, которые вводят внутривенно, перорально и даже подкожно, способны улучшать скорость опорожнения желудка и уменьшают проявления клинической симптоматики. Полученные результаты также свидетельствуют о высокой эффективности данной терапии, как метода коррекции избыточной массы тела не только при метаболическом синдроме, но даже при сахарном диабете.

Учитывая вышеизложенное, перспективным направлением является тщательное исследование роли грелина, а также показателей углеводного и липидного обмена в развитии и прогрессировании нарушений МЭФ желудка у пациентов с метаболическим синдромом.

\section{Цель исслеАования}

Изучить причины нарушения моторно-эвакуаторной функции у больных с МС.

\section{Материалы и метолы}

Всего было обследовано 75 пациентов с установленным диагнозом функциональной диспепсии в возрасте от 35 до 57 лет (39,7 $\pm 3,2$ года), которые были разделены на три группы. Все группы сравнения были однородны по полу и возрасту. Из них - 43 пациента с метаболическим синдромом (26 женщин, 17 мужчин), в зависимости от состояния МЭФ желудка были разделенные на две группы. В состав первой группы были включены пациенты $(n=19)$ без явных признаков изменения моторики желудка, тогда как во второй группе $(\mathrm{n}=24)$ - лица с клинически значимыми признаками замедления этого показателя. Третью группу составили 32 пациента с функциональной диспепсией, но без признаков МС (17 женщин и 15 мужчин), которым также определяли МЭФ желудка и ряд других показателей для сравнения с пациентами первых двух групп.

Для верификации диагноза проводили ряд лабораторных и биохимических исследований, определяли уровень глюкозы крови, гликированного гемоглобина (НbA1C), состояние липидного обмена, определяли HOMA-IR, а также уровень грелина. Оценивали показатели гастропанели (из исследования исключали пациентов с патологическими показателями гастрина, антителами к хеликобактерной инфекции и маркерами атрофии). Оценку клинических симптомов нарушения МЭФ желудка и длительности заболевания, выявляли при опросе с помощью стандартных анкет. Моторно-эвакуаторные нарушения диагностировали по результатам УЗИ МЭФ желудка. Для диагностики и исключения язвенно-эрозивных повреждений верхних отделов пищеварительного тракта, как причины диспепсических жалоб, проводилась фиброэзофагогастродуоденоскопию.

Из исследования исключались пациенты с гастроэзофагеальной рефлюксной болезнью, язвенными и эрозивными поражениями пищевода, желудка, двенадцатиперстной кишки, после оперативных вмешательств на органах пищеварительного тракта, нарушениями функции щитовидной железы, психическими заболеваниями, больные с почечной или печеночной недостаточностью, патологией соединительной ткани. Кроме того, исключались пациенты, принимающие ульцерогенные, слабительные, прокинетические, психотропные препараты, лица, злоупотребляющие алкоголем.

Статистическую обработку материала проводили при помощи Microsoft Excel с использованием пакетов статистического анализа Statistica 10. Пациенты подписывали информированное согласие на участие в исследовании.

\section{Результаты исслеАования и их обсужАение}

При детальном обследовании пациентов второй группы у 5 (20,8\%) больных с МС выявлено замедление МЭФ желудка легкой степени, у 11 (45,8\%) человек средней степени тяжести, тогда как только у 8 (33,3\%) пациентов выявлены тяжелые проявления. Характеристика показателей сывороточной концентрации гастроинтестинального гормона грелина в зависимости от состояния гликемии натощак, ИМТ, индекса HOMA-IR и уровня триглицеридов, ЛПНП, ЛПВП в группах сравнения представлена в таблице 1.

Одним из факторов подавления секреции грелина следует считать состояние инсулинорезистентности, по- 


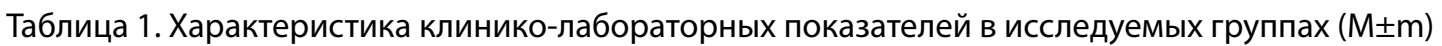

\begin{tabular}{|c|c|c|c|}
\hline Показатели & I группа (19) & II группа (24) & III группа (32) \\
\hline Пол (ж/м) & $11 / 8$ & $15 / 9$ & $17 / 15$ \\
\hline Возраст M \pm m & $39,6 \pm 5,36$ & $44,8 \pm 4,52$ & $41,3 \pm 1,22$ \\
\hline Длительность заболевания, годы & $3,4 \pm 2,13$ & $6,8 \pm 4,22$ & $2,5 \pm 1,31$ \\
\hline ИMT, кГ/M $\mathrm{M}^{2}$ & $36,5 \pm 3,84$ & $41,5 \pm 2,71^{*}$ & $20,8 \pm 1,42$ \\
\hline HOMA-IR & $2,87 \pm 1,98^{*}$ & $3,94 \pm 1,51^{*}$ & $1,37 \pm 0,92$ \\
\hline Гликемия натощак, ммоль/л & $6,6 \pm 0,51^{*}$ & $6,7 \pm 0,42^{*}$ & $3,5 \pm 0,23$ \\
\hline $\begin{array}{l}\text { Гликемия через } 2 \text { часа после ПГТТ, } \\
\text { ммоль/л }\end{array}$ & $9,4 \pm 1,01^{*}$ & $10,0 \pm 0,91^{*}$ & $5,6 \pm 0,64$ \\
\hline $\mathrm{HbA} 1 \mathrm{C}, \%$ & $4,82 \pm 1,98$ & $5,69 \pm 0,29$ & $4,42 \pm 0,24$ \\
\hline Общий холестерин, ммоль/л & $5,67 \pm 0,48$ & $6,29 \pm 0,41$ & $4,49 \pm 0,14$ \\
\hline ЛПВП, ммоль/л & $1,82 \pm 0,02$ & $1,32 \pm 0,07^{*}$ & $3,41 \pm 0,01$ \\
\hline ЛПНП, ммоль/л & $3,61 \pm 0,34$ & $4,12 \pm 0,51^{*}$ & $2,62 \pm 0,33$ \\
\hline Триглицериды, ммоль/л & $2,84 \pm 0,29$ & $3,59 \pm 0,37^{*}$ & $1,54 \pm 0,28$ \\
\hline Грелин, нг/мл & $35,81 \pm 3,72$ & $12,64 \pm 1,31^{*}$ & $69,34 \pm 3,24$ \\
\hline
\end{tabular}

* - p < 0,05 достоверная разница с показателями пациентов 3 группы без метаболического синдрома

скольку даже у пациентов первой группы при сравнении с третьей группой пациентов без МС наблюдается снижение концентрации данного гормона. Отсутствие связи между уровнем грелина и МЭФ желудка у пациентов первой группы на фоне сохранения моторики желудка, вероятно, можно объяснить длительностью заболевания, а также вероятным влиянием других гормонов, уровень которых не изучали в этом исследовании, например, мотилина и лептина.

Концентрация грелина у пациентов первой группы по сравнению с пациентами третьей группы без признаков МС снижена в 2 раза, тогда как у пациентов второй группы с признаками замедления МЭФ желудка имеется резкое достоверно значимое снижение $(p<0,05)$ содержания данного гастроинтестинального гормона. У пациентов с признаками гипертриглицеридемии обнаружена положительная корреляционная связь между уровнем триглицеридов и содержанием грелина $(r=0,51, p<0,05)$.

У пациентов второй группы содержание грелина составил 12,64+1,31 нг / мл, а по результатам УзИ желудка имелись признаки замедления МЭФ желудка преимущественно средней и тяжелой степени (79,2\%). Таким образом, состояние выраженной гипогрелинемии следует считать достоверным диагностическим маркером развития и прогрессирования нарушения моторно-эвакуаторной функции и ее клинической симптоматики при MC.

Множественный регрессионный анализ факторов, влияющих на концентрацию грелина, среди исследованных групп показал, что наиболее важные факторы, влияющие на его содержание были показатели ИМТ, инсулинорезистентность, индекс HOMA-IR, показатели липидного обмена. Этот показатель не зависел от гендерных факторов, длительности заболевания, а также других клинических проявлений МС.

По данным дополнительных методов обследования, выявлена прямая корреляционная связь между средним показателями клинического опросника и результатами УзИ желудка ( $r=0,63 \pm 0,03, p<0,001)$, а также выявлено сильная прямая связь $(r=0,73 \pm 0,02, p<0,001)$ между состоянием углеводного обмена и уровнем грелина. В условиях гипертриглицеридемии и гипогрелинемии наблюдалось прогрессирование моторно-эвакуаторных нарушений, что подтверждено результатами УЗИ желудка. У больных с МС и ИМТ выше 30,0 кг/м2 наблюдалось достоверное $(p<0,05)$ замедление опорожнения желудка сравнительно с пациентами третьей группы без МС или с пациентами первой группы у которых также выявлено снижение содержания грелина.

Результаты проведенного исследования свидетельствуют о низком содержании грелина в сыворотке крови всех больных с МС, что связано с замедлением метаболизма, который негативно влияет на организм в целом, способствует развитию тяжелой клинической симптоматики, в том числе и со стороны желудочно-кишечного тракта, является фактором нарушений углеводного и липидного обменов, приводит к прогрессированию метаболического синдрома и его осложнений.

\section{Выво $\triangle \mathrm{b}$}

У больных с метаболическим синдромом и функциональной диспепсией выявлено выраженное замедле- 
ние моторно-эвакуаторной функции желудка на фоне достоверно сниженного уровня грелина $(p<0,05)$. При сравнении полученных данных с показателями пациентов без признаков нарушений МЭФ, у которых уровень грелина также снижается, но статистически недостоверно при сравнении с пациентами без МС. Одним из факторов прогрессирования диспепсической симптоматики также следует считать и избыточную массу тела, так как наблюдается уменьшение концентрацией грелина у больных МС, а по результатам УЗИ подтверждено замедление моторики желудка. Наряду с прогрес- сированием гипогрелинемии, гипертриглицеридемия и показатели индекса HOMA-IR также способствует замедлению моторно-эвакуаторной функции желудка у больных с MC.

Перспективными исследованиями в дополнительном понимании нарушений моторно-эвакуаторной функции желудка у больных с МС и их лечения, является подбор патогенетической терапии с учетом нарушений липидного и углеводного обмена для коррекции проявлений метаболического синдрома.

1. Haslam D.W., James W.P. Obesity. Lancet 2005; 366 (9492): 1197-209.

2. Kojima M., Kangawa K. Ghrelin discovery: a decade after. Endocr Dev 2013; 25: 1-4.

3. Kojima M., Hosoda H., Matsuo H., et al. Ghrelin is a growth-hormone-releasing acylated peptide from stomach. Nature 1999; 402: 656-60.

4. Dockray G.J. Gastrointestinal hormones and the dialogue between gut and brain. J Physiol 2014; 592 (14): 2927-41.

5. Cohen P., Spiegelman B.M. Cell biology of fat storage. Mol Biol Cell 2016; 27 (16): 2523-7.

6. Sugrue M.L., Hollenberg A.N., Cone R.G., et al. Regulation of Thyrotropin-Releasing Hormone-Expressing Neurons in Paraventricular Nucleus of the Hypothalamus by Signals of Adiposity. Mol Endocrinol 2010; 24 (12): 2366-81.

7. Bernadette B. Thyroid and Obesity: An Intriguing Relationship. J Clin Endocrinol Metab 2010; 95 (8): 3614-7.

8. Shire A., Gumaa K., Giha H.A., et al. Association of Plasma Ghrelin Levels with Insulin Resistance in Type 2 Diabetes Mellitus among Saudi Subjects. Endocrinol Metab. (Seoul) 2017; 32 (2): 230-40.

9. Krauss H., Piątek M., Piątek J., et al. Fasting and postprandial levels of ghrelin, leptin and insulin in lean, obese and anorexic subjects. Prz Gastroenterol 2013; 8 (6): 383-9.

10. Flier J.S., Maratos-Flier E. Leptin's Physiologic Role: Does the Emperor of Energy Balance Have No Clothes? Cell Metab 2017; 26 (1): $24-6$.

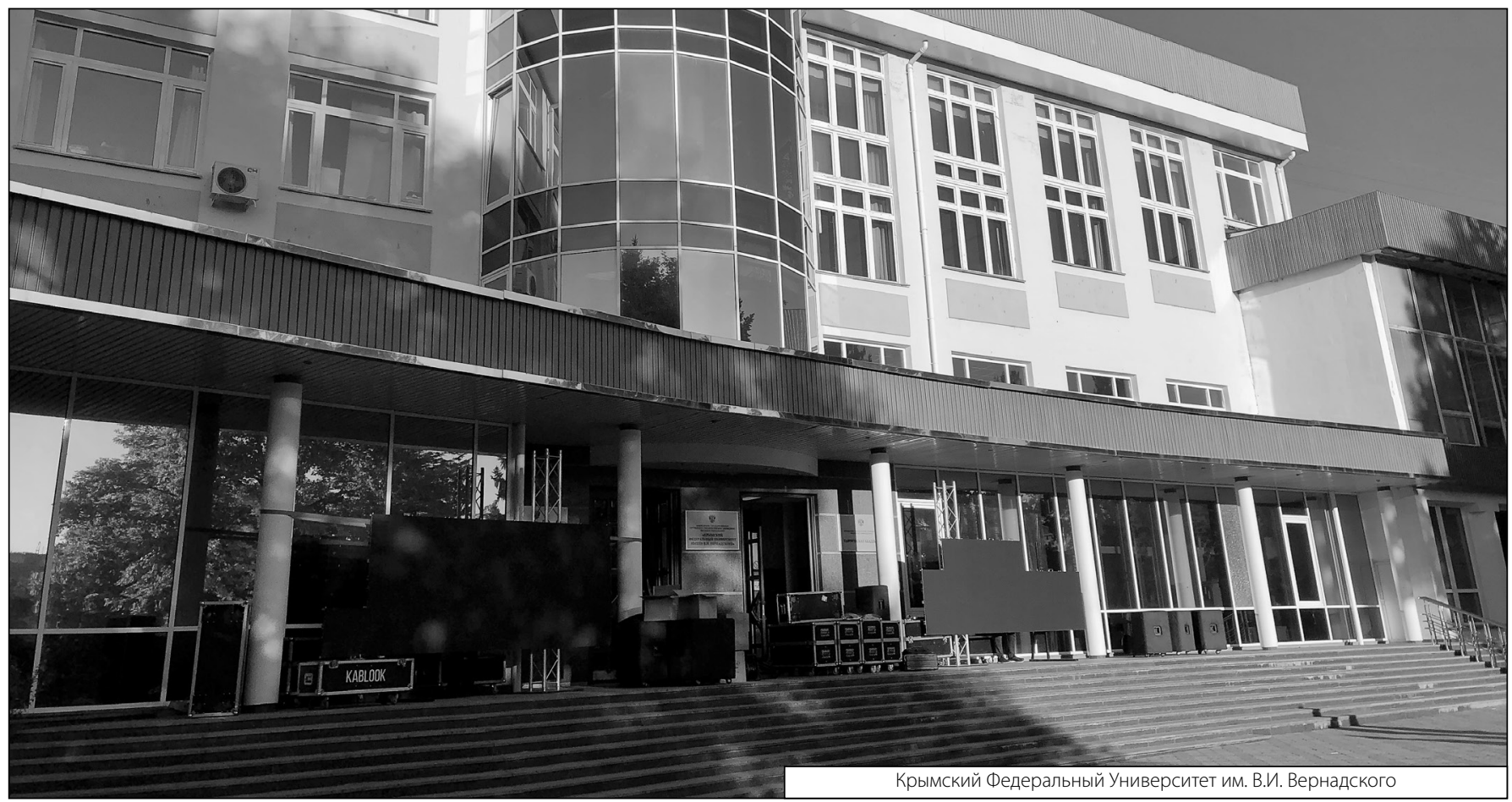

